\title{
Antimicrobial activity of citric acid against Escherichia coli, Staphylococcus aureus and Candida albicans as a sanitizer agent
}

\author{
Elif Ayşe Erdoğan Eliuz \\ Mersin University, Technical Sciences Vocational School, Department of Food Technology, TR-33343, Mersin, \\ Turkey \\ Corresponding author: eliferdogan81@gmail.com
}

\begin{abstract}
In this study, it was aimed to investigate the antimicrobial activity and inhibition percentage of citric acid against E. coli, S. aureus and C. albicans as a sanitizer agent. It was researched that persistent/tolerant levels of microorganisms in the citric acid presence. Spectrophotometric Broth Microdilution Method and Surface Disinfection Test were used for antimicrobial activity and Inhibition percentage, respectively. Modified TDtest was used for persistent/tolerant levels of microorganisms. While MIC (Minimum Inhibitory Concentration) of citric acid on E. coli and $S$. aureus were $0.06 \mathrm{~g} / \mathrm{mL}$, it was $0.03 \mathrm{~g} / \mathrm{mL}$ for C. albicans. It was applied the TDtest with citric acid solution and discriminate by tolerance level of $E$. coli than the other microorganisms at the end of the 48-h incubation. In a final test which was investigated the survival of E. coli, S. aureus and C. albicans exposure to citric acid by Surface Disinfection Test, there was no statistically significant difference between bacteria and yeast in terms of the number of inhibited cells. Although citric acid was rather active against all three microorganisms, the strongest and permanent antimicrobial effect was on C. albicans. Finally, citric acid should be used especially against anti-Candida albicans in permanent hygiene practices.
\end{abstract}

Keywords: Citric acid, E. coli, S. aureus, C. albicans, Persistent/tolerant, Sanitizer

\section{Introduction}

Citric acid known as tricarboxylic acid $\left(\mathrm{C}_{6} \mathrm{H}_{8} \mathrm{O}_{7}\right)$ is an preservative, acidulate, flavouring, emulsifier, sequestrate and buffering agent widely used across many industries such as food, beverage, pharmaceutical and cosmetic products (Thauer et al. 1988, Verhoff 2005). It is naturally found in Lime, Lemon, Raspberry, Tomato, Pineapple, strawberry, cranberry and was first crystallized from lemon juice and named by Scheele in Sweden in 1784 (Scheele 1784, Ciriminna et al. 2017). Colourless and odourless citric acid is slightly hygroscopic and highly soluble in water $\left(62.07 \%\right.$ at $\left.25^{\circ} \mathrm{C}\right)$ and slightly hygroscopic (Dalman 1937). Its environmentally benign nature and quickly degrades in surface waters besides useful Physico-chemical structure make it ideally suited for food, cosmetic and pharmaceutical applications. The code of citric acid is E330 as a food ingredient in European Union (E331 and E332, respectively, for sodium and potassium citrate) and has been Generally Recognized as Safe (GRAS) in the US (Ciriminna et al. 2017). Citric acid's popularity has increased even more in household detergents and home hygiene because of restrictions on the use of phosphate in dishwasher detergents in the US (since 2010), EU (Ciriminna et al. 2017) and Turkey (Official Newspaper 2018).This situation has caused the citric acid market to take more place in the industrial field and will follow. It was shown that citric acid has an excellent antiviral disinfectant effect and reported to irreversibly disturb the virus's 
structure. For this reason, it has been suggested that it can be used for permanent disinfection on the infected surfaces (Koromyslova et al. 2015).

It is industrially added to juices in the beverage industry and is widely used to increase the stability of concentrates. At the same time, thanks to its antioxidant and antimicrobial properties against foodborne pathogens such as Escherichia coli, Salmonella, Listeria, monocytogenes., it prevents spoilage and keeps the drink fresh (Rossle et al. 2009; Ciriminna et al. 2017). Besides, it is stated that will be needed more biotechnological products such as citric acid which do not have serious harm to nature and human, and which have useful powerful effects, in the future (Ciriminna et al. 2016).

Insufficient hygiene of food processing products and surfaces contributes to long-term surface trapping of pathogen microorganisms, cross-contamination and irreversible food contamination (Carpentier and Cerf 1993). Therefore, surfaces often are disinfected with many active chemicals, but most of the chemicals pose a concern for food safety as they leave residue and pose a threat to health (Akinyemi et al. 2006). Therefore, the importance of naturally originated antimicrobials is increasing day by day (Nural et al. 2018; Yabalak et al. 2020). Besides, microorganisms' gaining resistance against these chemicals over time makes more difficult achieve sufficient and permanent hygiene (Notermans et al. 1991).

In the present paper, it was first investigated the tolerance or persistence levels in E. coli, S. aureus and C. albicans exposed to the solution according to the modified Kirby-Bauer disk diffusion method besides evaluating the antimicrobial actitivity of citric acid as a sanitizer agent.

\section{Materials and Methods}

\section{Materials and instruments}

Mueller Hinton Broth (MHB), Mueller Hinton Agar (MHA), Triptic Soy Broth (TSB), Sabouraud Dextrose Broth (SDB), were supplied from Merck (Germany). E. coli (ATCC 25293), S. aureus and $C$. albicans were taken from Refik Saydam Hifzıssıhha Centre (Turkey). ELIZA spectrophotometer (MULTISKAN GO, Thermo Scientific) was used for antimicrobial measurements. Citric acid was purchased from Sigma.

\section{Preparing the citric acid solution}

To prepare the citric acid solution, $1 \mathrm{~g}$ citric acid was weighed and added to $30 \mathrm{~mL}$ of previously sterilized distilled water. It was then homogenized in the magnetic stirrer for 1 hour and stored at $4{ }^{\circ} \mathrm{C}$. The $\mathrm{pH}$ value of citric acid in water was determined using Ph meters.

\section{Antimicrobial screening}

The inoculums of Escherichia coli (ATCC 25293), Staphylococcus aureus (ATCC 25923) and Candida albicans (ATCC 90028) were prepared in $4 \mathrm{~mL}$ TSB for bacteria and $4 \mathrm{~mL}$ SDB for yeast and incubated at $37^{\circ} \mathrm{C}$, overnight. After 24 hours, the microorganism suspensions were adjusted to $0.5 \mathrm{McFarland}$ Standard Turbidity and stored at $+4{ }^{\circ} \mathrm{C}$ until experiments.

\section{Broth Microdilution Method}

The $50 \mu \mathrm{L}$ of MHB medium were added into 96-well microtiter plates and two-fold serial dilutions of $50 \mu \mathrm{L}$ citric acid solution were made $\mathrm{x}$-axis along from 2 nd to 10 th columns and used columns 11 and 12 as the negative control (only MHB and microbe). Then, $5 \mu \mathrm{L}$ cultures were inoculated on all wells except negative control. As positive controls, Ampicillin (AMP: $128 \mu \mathrm{g} / \mathrm{mL}$ ) in bacteria and Fluconazole (FLC: $128 \mu \mathrm{g} / \mathrm{mL}$ ) in yeast were used. Finally, all plates were incubated at $37^{\circ} \mathrm{C}$ for 24 hours and the growth (turbidity) was measured at $615 \mathrm{~nm}$. MIC was determined as the lowest concentration where no visible turbidity was observed in the each in each row of the 96-well plate.

\section{Modified TDtest (Tolerance Disc Test)}

To evaluate tolerance or persistence levels in E. coli, S.aureus and C. albicans against citric acid was used by TDtest (Kirby-Bauer disk diffusion method modified). This method consists of two steps: First, the MIC values of citric acid were used for the well diffusion method. For this, the cultures at stationary phase were spread onto MHA plates and $6 \mathrm{~mm}$ diameter wells were drilled into the middle of them. The 
$50 \mu \mathrm{L}(0.1 \mathrm{~g} / \mathrm{mL})$ of citric acid was placed in the wells and incubated at $37^{\circ} \mathrm{C}$ for $24 \mathrm{hrs}$. Second: $50 \mu \mathrm{L}$ glucose $(10 \%)$ was placed in the well which discharged because of the diffusion of the citric acid solution into the agar. The alteration in the zone regions of the petri dishes re-incubated during $37^{\circ} \mathrm{C}$ for $24 \mathrm{hrs}$ was measured and compared with the clear zone in the primary step. TDtest, which citric acid was replaced with the glucose, allows re-growth and detection of the surviving bacteria on the agar surface. According to the method, it is interpreted as susceptible strain if inhibition zone were found around the well after glucose addition and tolerant strain if colonies inside the clear zone after glucose (Figure 1) (Gefen et al. 2017).

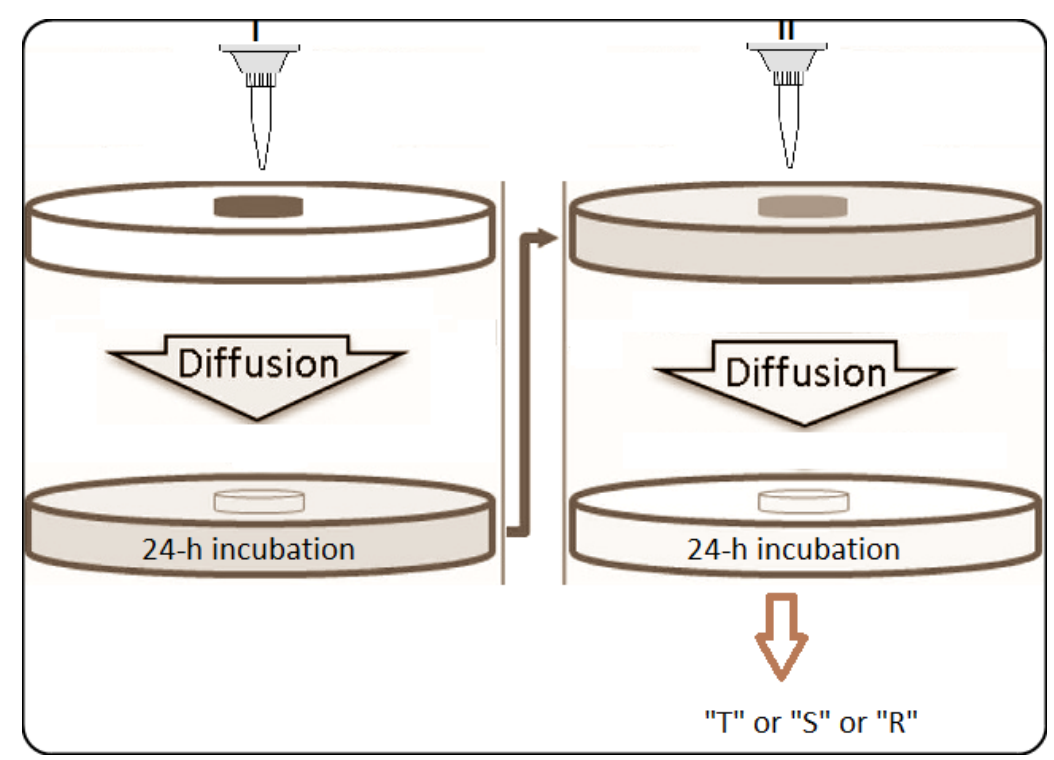

Fig 1. The diagram of the modified TDtest. Application of citric acid on the agar well (I), Replacing the citric acid with glucose solution (II). "T", "S", "R" Susceptible strain (S): no colonies in the inhibition zone around well after glucose addition. Tolerant strain (T): Colony observation in inhibition zone after glucose.

\section{Surface Disinfection Test}

Surface sanitizer tests were performed using the EN 13697:2015 standard "Chemical disinfectants and antiseptics. Quantitative non-porous surface test for the evaluation of microsidal activity of chemical disinfectants used in many industries such as food, cosmetic and agricultural. Test method and requirements without mechanical action". The microcidal activity of citric acid as a sanitizer (C-SAN) was evaluated on glass lam. Lams were sterilized at $121^{\circ} \mathrm{C}$ for $15 \mathrm{~min}$ in an autoclave before each assay. Briefly, E. coli and S.aureus and C. albicans suspensions were diluted (ratio 1:1) with 0.3 and $3 \mathrm{~g} / \mathrm{l}$ bovine serum albumin (BSA) to mimic dirty and clean working conditions (as in EN 13697:2015), respectively. Then $50 \mu 1$ of resulting inocula $(8 \log \mathrm{CFU} / \mathrm{ml})$ were spotted into sterile lams and dried at RT for $15 \mathrm{~min}$. Later, $50 \mu \mathrm{l}$ of $10 \% \mathrm{C}$-SAN was prepared on hard water as diluents according to EN 13697:2015 and $50 \mu 1$ mixture was transferred to 96-ELISA plates by mixing with a pipette and $50 \mu 1$ TTC (2,3,5- triphenyl tetrazolium chloride) was added. Plates were incubated at $37^{\circ} \mathrm{C}$ to be visualized by staining with TTC and after 4 hours, spectrophotometric measurements were made at $485 \mathrm{~nm}$. Although there were no C-SAN agents studied in the negative control well, other conditions were the same.

For percent of inhibition was calculated according to the following formulae (1);

Percent of Inhibition $(\%)=\left[1-\frac{O D_{\text {test well }}}{O D_{\text {corresponding control well }}}\right] \times 100$ 


\section{Statistical analysis}

Statistical analyses and significance were measured by Tukey test in one way analysis of variance for MICs and IZ using SPSS 25. Differences were considered significant at $\mathrm{p} \leq 0.05$.

\section{Result and Discussion}

\section{Antimicrobial activity and response of microorganisms according to TDTest}

The results showed that citric acid was effective against $E$. coli, S. aureus and $C$. albicans by broth microdilution and agar well diffusion method (Table 2). There was a statistically significant difference between bacteria and yeast in terms of MICs of citric acid. While MIC of citric acid on E. coli and $S$. aureus were $0.06 \mathrm{~g} / \mathrm{mL}$, it was $0.03 \mathrm{~g} / \mathrm{mL}$ for C. albicans. In the present study, it was seen a statistically significant difference between inhibition zones at the end of the 24-h incubation $(p<0.05)$. The highest inhibition zone was found with $8.33 \mathrm{~mm}$ on $C$. albicans while the lowest IZ with $2.41 \mathrm{~mm}$ on S. aureus and also it was 4.56 on $E$. coli by well diffusion agar test $(\mathrm{p}<0.05)$. Among bacteria, citric acid more affected $E$ coli from $S$. aureus $(\mathrm{p}<0.05)$.

It was applied the TDtest with citric acid solution and discriminate by tolerance level (T) of E. coli than the other microorganisms at the end of the 48-h incubation (Table 2). At the end of the 48-h incubation, the inhibition zones were found as $8.30 \mathrm{~mm}, 2.07 \mathrm{~mm}, 4.27 \mathrm{~mm}$ for C. albicans, S. aureus and E. coli, respectively $(\mathrm{p}<0.05)$.

Table 1. Minimal Inhibition Concentration and inhibition zone $(\mathrm{mm})$ of citric acid against E. coli, S. aureus and C.

albicans. Res: Response of microorganisms in step 2 according to TDTest, S: Susceptible strain; T: Tolerant strain.

\begin{tabular}{llll}
\multicolumn{4}{c}{ citric acid pH: $\mathbf{1 . 8 2}$} \\
\hline & MIC $(\mathbf{g} / \mathbf{m L})$ & & IZ $(\mathbf{4 8} \mathbf{~ h})-\mathbf{R e s}$ \\
E. coli $($ Gram -$)$ & $0.06^{\mathrm{a}} \pm 0.01$ & $4.56^{\mathrm{b}} \pm 0.03$ & $4.27^{\mathrm{b}} \pm 0.08-\mathbf{T}$ \\
S. aureus $($ Gram +) & $0.06^{\mathrm{a}} \pm 0.02$ & $2.41^{\mathrm{a}} \pm 0.02$ & $2.07^{\mathrm{a}} \pm 0.02-\mathrm{S}$ \\
C. albicans & $0.03^{\mathrm{b}} \pm 0.1$ & $8.33^{\mathrm{b}} \pm 0.01$ & $8.30^{\mathrm{b}} \pm 0.03-\mathrm{S}$ \\
\hline
\end{tabular}

The average MICs were expressed with the standard deviation ( \pm ) and significance level (ANOVA, 25; 0.05, Tukey test). Values on the same column with different superscript letters differ statistically at the 0.05 level. The MICs of positive control: E. coli $(16 \mu \mathrm{g} / \mathrm{mL})$, S. aureus $(16 \mu \mathrm{g} / \mathrm{mL})$ and C. albicans $(128 \mu \mathrm{g} / \mathrm{mL})$. The IZs of positive control: E. coli $(10.1 \mathrm{~mm}), S$. aureus $(7.7 \mathrm{~mm})$ and $C$. albicans $(1.1 \mathrm{~mm})$.

The solution had a strong and persistent antibacterial against $C$. albicans and $S$. aureus. The sensitivities of $C$. albicans and $S$. aureus can be presented as follows: C. albicans $>S$. aureus. Finally, it was determined that $E$. coli was tolerance to citric acid because of a few colonies in the inhibition region (Figure 2).

\section{Evaluation of inhibition activity of C-SAN}

Survival of E. coli, S. aureus and C. albicans were investigated by surface disinfection test exposure to C-SAN. The percentages of inhibition were used to assess the number of cells that died after 4 hours compared with negative control (live of $100 \%: 8 \mathrm{log}$ ). There was no statistically significant difference between bacteria and yeast in terms of the number of inhibited cells. In glass surface which mimicking dirty working conditions ( $3 \mathrm{~g} / \mathrm{mL}$ BSA), while the inhibition order is presented: $S$. aureus $(47.06 \%)>$ E. coli $(41.33 \%)>$ C. albicans $(36.23 \%)$; It is $C$. albicans $(46.03 \%)>S$. aureus $(43.16 \%)>$ E. coli $(35.3 \%)$ in clean working conditions $(0.3 \mathrm{~g} / \mathrm{mL} \mathrm{BSA})$ (Figure 3$)$.

\section{Discussion}

In literature, there are studies in which MIC values of citric acid are determined against E. coli, S. aureus and $C$. albicans. For instance, Nagoba et al. (2008) found the MIC of citric acid to be $900 \mathrm{mg} / \mathrm{mL}$ for S. aureus and $1500 \mathrm{mg} / \mathrm{mL}$ for E. coli (Nagoba et al. 2008). 


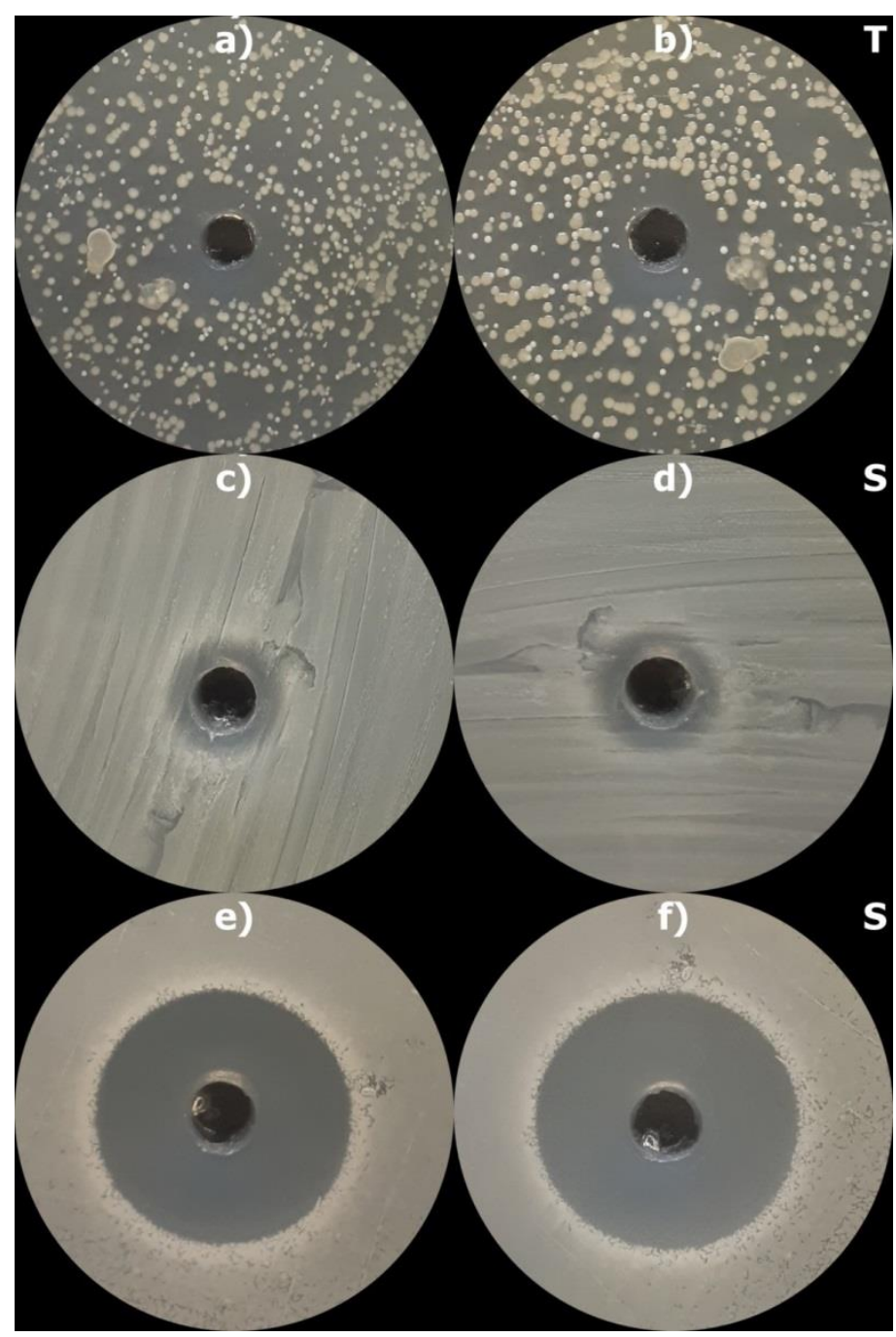

Fig 2. The images of tolerance and sensitivity levels of E. coli (a,b), S. aureus (c,d) and C. albicans (e,f) in exposure to citric acid. The first (a, c, e) and second (b, d, f) step of TDtest, S: Susceptible strain; T: Tolerant strain.

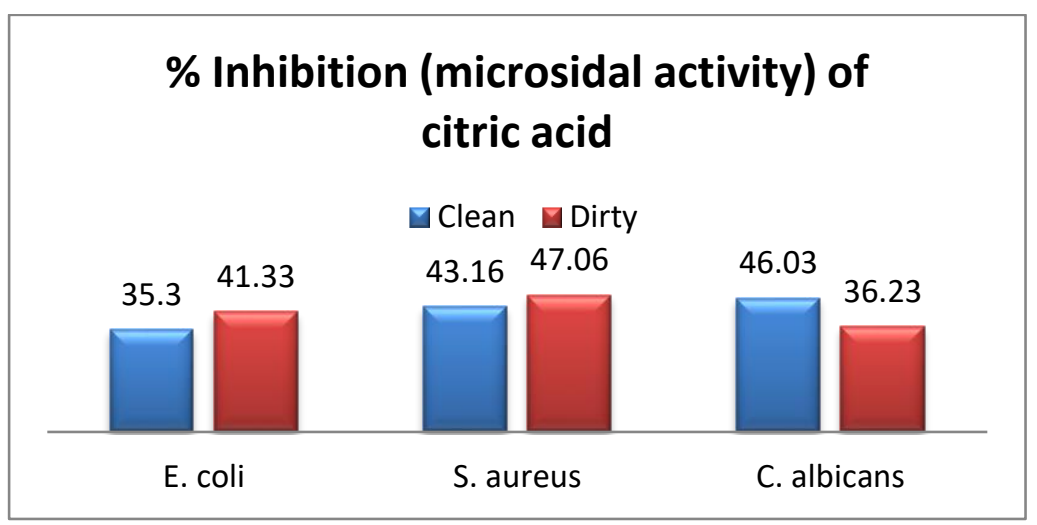

Fig 3. Microcidal activity (\%) of citric acid against E. coli, S. aureus and C. albicans on a glass surface clean (0.3 g/mL BSA) and dirty (3 g/mL BSA) conditions at 4-h contact times according to EN 13697:2015. Values with same superscript letters don't differ statistically at the 0.05 level.

In a study which the antimicrobial activity of some organic acid including monolaurin citric acid, MIC was $>5 \mathrm{mg} / \mathrm{ml}$ against Escherichia coli (Skrivanova et al. 2006). Citric acid was active with MIC of 2$10 \mathrm{mg} / \mathrm{mL}$ against $C$. albicans and some fungi species (Shokri 2011). As also in this study (MICs: 0.03$0.06 \mathrm{~g} / \mathrm{mL}$ ), low MIC values of citric acid are due to being a low $\mathrm{pH}$ organic acid of acid. Generally, 
organic acids inhibit microorganisms through a process which the acid $\mathrm{pH}$ within the cell induces breakdown and harm to enzymatic activity, proteins and DNA molecular structure or disturb the electron transport system thereby destroying the extracellular membrane (Mani-Lopez et al. 2012). Also, some organic acid such as citric acid, lactic acid, propionic acid, malic acid and tartaric acid have been shown to reduce microbial load on foods (Park et al. 2011).

The disc-diffusion test used in antimicrobial activities assesses only the concentration, namely the degree of resistance, at which the microorganism prevents proliferation. TDtest was also created with the technical development of this test. This method has made it possible to detect tolerant and persistent microorganisms by encouraging the growth of the surviving microorganisms in the inhibition zone after the antimicrobial agent has spread (Gefen et al. 2017). In literature, Kotkova et al., (2019) tried the TDTest for persistence or tolerance of $S$. aureus strain against $1 \mu \mathrm{g}$ oxacillin and they showed that $S$. aureus was tolerant against this antibiotic and also this test was suitable for persistent/tolerant screening for clinic strains. However, in this study, $S$. aureus was permanent sensitive to citric acid and no colony was found even in the 48 -h incubation. Especially, inhibition zone $(8.33 \mathrm{~mm})$ of citric acid against Candida albicans at the end of the 24-h incubation and the permanent inhibition $(8.30 \mathrm{~mm})$ observed although glucose was replaced with citric acid to encourage the reproduction of microorganism in the continuation of incubation, is remarkable. However, it was found $E$. coli to be tolerant compared to $S$. aureus and C. albicans. It can be suggested that this is related to the cell wall.

In surface disinfection test, the percentages of inhibition of E. coli, S. aureus and C. albicans exposure to C-SAN (pH: 1.82) were investigated and this rate changed between $35.3 \%$ and $47.06 \%$ at the end of the 4 hours. This indicates that almost half of the microorganisms are inhibited after 4 hours. No previous study has been carried out percent inhibition of this acid on microorganisms at 4-hours incubation. However, there are 24-hour inhibition studies and a few examples can be given. In a paper, citric acid $(0.03 \%)$ did not inhibit the growth of E. coli, while it reduced the growth of $S$. aureus and the percentage of inhibition after $24 \mathrm{~h}$ incubation in nutrient broth were $33 \%$, respectively (AbuGhazaleh 2013). In this study, the percentage of inhibition against S. aureus was below 50\%, although the incubation time was shorter. This can indicate that inhibition of microorganisms occurs within the first few hours. No Candida inhibition studies were found.

These results show that citric acid has a strong antimicrobial effect and this effect is permanent for $S$. aureus and C. albicans. Hence it is concluded that citric acid application everywhere contaminated with pathogens can be generalized in case of detailed studies on human health.

\section{Conclusion}

In this study, the antimicrobial effect of citric acid on E. coli, S. aureus and C. albicans was investigated and it was checked whether this effect was permanent or tolerant according to TDTest method. In the study, the highest effect was on $C$. albicans and it was determined that $C$. albicans showed permanent sensitivity to citric acid. At the same time, the modified surface sanitizer test was measured at the 4th hour, when viable microorganisms can be stained with TTC dye, and at the end of this period, approximately half of the microorganisms were inhibited. As a result, it is a persistant antimicrobial agent, especially for Candida contamination, that can be used in place of hazardous chemicals that may be toxic to the human cell on all surfaces at risk of germ contamination.

\section{References}

Abu-Ghazaleh, B.M. (2013). Effects of ascorbic acid, citric acid, lactic acid, NaCl, potassium sorbate and Thymus vulgaris extract on Staphylococcus aureus and Escherichia coli. African Journal of Microbiology Research 7: 712. 
Akinyemi, K. O., Oluwa, O. K. and Omomigbehin, E. O. (2006). Antimicrobial activity of crude extracts of the three medicinal plants used in South-West Nigerian folk medicine on some food borne bacterial pathogens. African Journal of Traditional, Complementary and Alternative Medicines 3:13-22.

Carpentier, B. and Cerf, O. (1993). Biofilms and their consequences, with particular reference to hygiene in the food industry. Journal of Applied Microbiology 75: 499-511.

Ciriminna, R., Albanese, L., Meneguzzo, F. and Pagliaro, M. (2016). Hydrogen peroxide: a key chemical for today's sustainable development. Chem Sus Chem 9: 3374-3381.

Ciriminna, C.R, Meneguzzo, F., Delisi, R. and Pagliaro M. (2017). Citric acid: Emerging applications of key biotechnology industrial product. Chemistry Central Journal 11: 1-9.

Dalman, L.H. (1937). The solubility of citric and tartaric acids in water. Journal of the American Chemical Society 59: 2547-2549.

Gefen, O., Chekol, B., Strahilevitz, J. and Balaban, N. Q. (2017). TDtest: Easy detection of bacterial tolerance and persistence in clinical isolates by a modified disk-diffusion assay. Scientific Reports 7: 41284.

Koromyslova, A. D., White, P. A. and Hansman, G. S. (2015). Treatment of norovirus particles with citrate. Virology 485: 199-204.

Kotková, H., Cabrnochová, M., Lichá, I., Tkadlec, J., Fila, L., Bartošová, J. and Melter, O. (2019). Evaluation of TD test for analysis of persistence or tolerance in clinical isolates of Staphylococcus aureus. Journal of Microbiological Methods 167: 1-6.

Mani-Lopez, E., Garcia, H. S. and Lopez-Malo, A. (2012). Organic acids as antimicrobials to control Salmonella in meat and poultry products. Food Research International 45: 713-721.

Nagoba, B. S., Gandhi, R. C., Wadher, B. J., Potekar, R. M. and Kolhe, S. M. (2008). Microbiological, histopathological and clinical changes in chronic infected wounds after citric acid treatment. Journal of Medical Microbiology 57: 681-682.

Notermans, S., Dormans, J. A. M. A. and Mead, G. C. (1991). Contribution of surface attachment to the establishment of microorganisms in food processing plants: A review, Biofouling 5: 21-36.

Nural Y., Gemili M., Yabalak E., De Coen L.M., Ulger M. (2018). Green synthesis of highly functionalized octahydropyrrolo[3,4-c]pyrrole derivatives using subcritical water, and their anti(myco)bacterial and antifungal activity. The Free Internet Journal for Organic Chemistry 18-10573IP: 51-64.

Official Newspaper. (2018). https://www.resmigazete.gov.tr/eskiler/2018/01/20180127-1.htm (Visited on date 14/05/2020).

Park, S. H., Choi, M. R., Park, J. W., Park, K. W., Chung, M. S., Ryu, S. R. and Kang, D. H. (2011). Use of organicacids to inactivate Escherchia coli O157:H7, Salmonella typhimurium, and Listeria monocytogenes on organic fresh apples and lettuce. Journal of Food Science 76: 293-298.

Rossle, C., Gormley, T. R. and Butler, F. (2009). Efficacy of Natureseal AS1 browning inhibitor in fresh-cut fruit salads applications, with emphasis on apple wedges. The Journal of Horticultural Science and Biotechnology 84: $62-67$.

Scheele, C.W. (1784). Anmärkning om Citron-Saft, samt sätt att crystallisera den samma" (Note on lemon juice, as well as ways to crystallize the same). Kongl Vetenskaps Academiens Nya Handlingar 5:105-109.

Shokri, H. (2011). Evaluation of inhibitory effects of citric and tartaric acids and their combination on the growth of Trichophyton mentagrophytes, Aspergillus fumigatus, Candida albicans, and Malassezia furfur. Comparative Clinical Pathology 20, 543-545.

Skrivanova, E., Marounek, M., Benda, V. and Brezina, P. (2006). Susceptibility of Escherichia coli, Salmonella sp.and Clostridium perfringens to organic acids and monolaurin. Veterinární medicína 51:81-88.

Thauer, R.K. (1988). Citric-acid cycle, 50 years on. European Journal of Biochemistry 176: 497-508.

Verhoff, F.H. (2005). Citric acid, Ullmann's encyclopedia of industrial chemistry. Wiley- VCH, Weinheim.

Yabalak, E., Emire, Z., Adıgüzel, A.O., Könen adigüzel, S., Gizir, A. M. (2020). Wide-scale evaluation of Origanum munzurense Kit Tan \& Sorger using different extraction techniques: Antioxidant capacity, chemical compounds, trace element content, total phenolic content, antibacterial activity and genotoxic effect.Flavour and Fragrance Journal 35: 394-410.

Submitted: 28.08.2020 Accepted: 30.09.2020 